\title{
PERSISTENT POST SURGICAL PAIN
}

\author{
Dr Victor Mendis* \\ Consultant in Pain Medicine \& Anaesthetics, Mid Essex NHS Trust, UK \\ *Corresponding author E-mail: victormendis1@yahoo.co.uk
}

Key words: pain, neuropathic, postsurgical

Persistent Post Surgical Pain is a chronic pain condition resulting from surgery. Although largely unrecognised in the past, there is more awareness of the problem recently. It is thought that between $10-50 \%$ of individuals can develop persistent post surgical pain after common operations such as groin hernia repair, breast and thoracic surgery, leg amputation, and coronary artery bypass surgery. ${ }^{1}$ It is a consequence of neuropathic pain as a result of injury to major peripheral nerves although very rarely it could be due to ongoing inflammation. Table 1 shows the prevalence of chronic pain following surgery.

Table 1 Prevalence of chronic pain following surgery

\begin{tabular}{|l|l|l|}
\hline \multirow{2}{*}{ Surgery } & Perkins and Kehlet & Macrae \\
\hline Breast & $11-49 \%$ & $23-49 \%$ \\
\hline Thoracotomy & $22-67 \%$ & $5-67 \%$ \\
\hline Cholecystectomy & $3-56 \%$ & $3.4-27 \%$ \\
\hline Inguinal hernia & $0-37 \%$ & $15-63 \%$ \\
\hline Vasectomy & N/A & $0-37 \%$ \\
\hline
\end{tabular}

(Adapted from Wilson JA et al: Acute neuropathic pain after surgery. Bulletin 15, The Royal College of Anaesthetists, September 2002)

Activation of nociceptors in the immediate postoperative period leads to an inflammatory response and this "nociceptive" pain usually responds to nonsteroidals and anti-inflammatory analgesics. If however as a result of nerve injury, a neuropathic pain were to develop, this would persist in the absence of ongoing inflammation and be resistant to conventional analgesics. It is therefore important to differentiate neuropathic pain from non-neuropathic pain in order to be able to have effective strategies to prevent and treat this condition. The degree of nerve damage correlates with the intensity of chronic pain as shown in changes in sensory threshold and somatosensory evoked responses to electrical stimulation in the thoracotomy scar area. ${ }^{2}$

\section{Risk factors}

Risk factors for developing persistent post surgical pain have been identified and have been classified into blue, yellow and red flags. The blue flags are perioperative risk factors, yellow flags the psychological and environmental factors and red flags the postoperative physical disorders.

\section{Blue flags \\ Pre-existing chronic pain \\ Younger age \\ Female sex \\ Site and extent of surgery \\ Pain before surgery}

Previous pain correlates with the development of chronic neuropathic pain. Severe post herpetic neuralgia is often preceded by severe zoster pain. ${ }^{3,4}$ Amputees with severe phantom limb pain have more often had intense and enduring preamputation pain than amputees with less intense phantom pain., ${ }^{5,6}$ Uncontrolled acute postoperative pain also predisposes to subsequent chronic post surgical pain. Younger age predisposes to developing persistent post surgical pain. In postherniorrhaphy pain older patients have a reduced risk of developing chronic pain. ${ }^{7,8}$. Other factors such as site and extent of surgery and reoperations are thought to predispose to developing persistent postsurgical pain.

\section{Yellow flags \\ Psychological factors \\ Emotions \\ Perceptions \\ Past experiences}


Attitudes and concerns and beliefs

Preop anxiety

Environmental factors

Low self rated esteem

Income

Level of education

Relationship issues (divorced/separated)

Expectation of pain, fear, past memories, social environment, work and levels of physical activity, all affect the response to noxious stimuli. ${ }^{9,10}$ Preoperative anxiety is correlated with | postoperative pain experience. $\frac{11,12}{}$

\section{Genetic susceptibility}

Genetic susceptibility may explain the reason why only a proportion of patients with intraoperative nerve damage develop chronic pain, It is thought that there is a differential heritable susceptibility both to the generation and experience of pain, as well as to the response to analgesics. ${ }^{13-17}$ Results of studies in rodents indicate that the susceptibility to develop neuropathic pain has a strong heritable component, but the genes responsible have yet to be identified. ${ }^{18,19,20}$

\section{Red flags}

Infection

Bleeding

Organ rupture

Compartment syndrome

Postoperative physical factors stated above will predispose to a higher incidence of developing persistent post surgical pain.

\section{Predicting persistent post surgical pain}

Scoring systems based on age, sex, type of surgery, level of preoperative anxiety have been developed to attempt to predict early postoperative pain. $^{21}$

Preoperative nociceptive stimulation tests have also been used either using a heat stimulus before knee surgery ${ }^{22}$ or an ice water test in patients undergoing laparoscopic cholecystectomy ${ }^{23}$ and a positive correlation noted between preoperative pain response and degree of early postoperative pain. These preoperative tests can be used to identify those patients who are likely to develop early postoperative pain and hence can be used to predict the risk of developing persistent post surgical pain. Preoperative catastrophising is known to be correlated with the intensity of acute postoperative pain. ${ }^{24}$

If such patients can be identified, measures can be taken to try and prevent the development of persistent post surgical pain.

\section{Prevention}

\section{Preoperative assessment}

The preanaesthetic assessment and consultation helps to allay anxiety and fears about surgery and anaesthesia. The anaesthetist during the preoperative visit should discuss analgesic regimes, recovery and postoperative pain relief and reassure the patient. Assurance from the anaesthetist is thought to contribute to a better recovery.

\section{Surgical technique}

Minimising damage to major peripheral nerves is important and therefore minimally invasive techniques have shown to reduce the risk of developing chronic pain. It has been shown that laparoscopic herniorrhaphy reduces the risk of nerve damage and pain compared with open surgery. ${ }^{25}$ The use of light weight mesh for inguinal hernia repair is supposed to reduce the inflammatory response and so reduce the risk of post op pain. ${ }^{26}$ Thoracoscopic techniques that reduce damage to intercostal nerves have been shown to be superior than open surgery. ${ }^{27}$

\section{Education and effective analgesia}

Education of the medical and nursing staff about the importance of managing pain in the immediate postoperative period is of utmost importance. Results from a UK based national survey showed that pain continues to be undermanaged and that $80 \%$ of postoperative patients still experience pain and of this $86 \%$ reported their pain to be moderate or severe. ${ }^{28}$ If pain is to be treated adequately it has to be measured and for this reason, it has been suggested pain to be considered as the "fifth vital sign” alongside with heart rate, blood pressure, temperature and respiratory rate. Aggressive pain management in the acute postoperative period is important but whether techniques such as preemptive or preventive analgesia producing a meaningful reduction in chronic pain is unclear. $^{29,30}$ Multimodal approaches using 
ketamine $^{31}$ and other N-methyl-d-aspartate receptor antagonists as well as antineuropathic medications such as gabapentin and pregabalin ${ }^{32}$ in the perioperative period have the potential to prevent central neuroplasticity and need further investigation.

\section{Conclusion}

Prevention of Persistent Post Surgical Pain depends on awareness amongst surgeons about using minimally invasive surgical techniques, careful preoperative preparation of patients and optimal anaesthetic and pain management in the perioperative period. Identifying those at possible risk of developing postoperative chronic pain and managing them is also very important. More recently, Persistent Post Surgical Pain has been described as a neurodegenerative disorder that requires neuroprotective treatment. ${ }^{1}$ This would involve modalities aimed at reducing the neuroplastic changes that occur within the nervous system with time and just controlling pain alone in the perioperative period may not be adequate.

\section{References}

1. Henrik Kehlet, Troels S Jensen, Clifford J Woolf. Persistent Post Surgical Pain: risk factors and prevention. Lancet 2006;367:1618-25

2. Benedetti F, Vighetti S, Ricco $C$ et al Neurophysilogic assessment of nerve impairement in posterolateral and muscle sparing thoracotomy. $J$ thorac Cardiovasc Surg 1998;115:841-47

3. Dworkin RH, Hartstein G, Rosner HL, walther RR, Sweeney EW, Brand L. A high-risk method for studying psychosocial antecedants of chronic pain: the prospective investigation of herpes zoster. $J$ Abnorm Psychol 1992;101:200-05

4. Jung BF,Johnson RF, Griffin DRJ, Dworkin RH. Risk factors for post herpetic neuralgia in patients with herpes zoster. Neurology 2004;62:1545-51

5. Jensen TS, Krebs B, Nielsen J, Rasmussen P. Immediate and long term phantom limb pain in amputees: incidence, clinical characteristics and relationship to preamputation limb pain. Pain 1985;21:267-78

6. Nikolajsen L, Ilkjaer S, Kroner K, Christensen $\mathrm{JH}$, Jensen TS. The influence of preamputation pain on postamputation stump and phantom pain. Pain 1997;72:393-405
7. Aasvang E, Kehlet II. Chronic postoperative pain: the case of inguinal herniorrhaphy. $\mathrm{Br} J$ Anaesth 2005;95:69-76

8. Poobalan AS, Bruce J, Smith WC, King PM, Krukowski ZH, Chambers WA. A review of chronic pain after inguinal herniorrhaphy. Clin J Pain 2003;19:48-54

9. Linton SJ, Overmeer T, Janson M, Vlaeyen JWS, de Jong JR, Graded in vivo exposure treatment for fear-avoidant pain patients with functional disability: a case study. Cogn Behav Ther 2002;31:49-58

10. Vlaeyen JW, Linton SJ. Fear avoidance and its consequences in chronic musculoskeletal pain: a state of the art. Pain 2000;85:317-32

11. Caumo W, Schmidt AP, Schneider CN, et al. Preoperative predictors of moderate to intense acute postoperative pain in patients undergoing abdominal surgery. Acta Anaesthesiol Scand 2002;46:1265-71

12. Katz J, Poleshuck EL, Andrus CL, et al. Risk factors for acute pain and its persistence following breast cancer surgery. Pain 2005; 119:16-25

13. Hartvigsen J, Christensen K, Frederiksen H, Pedersen HC. Genetic and environmental contributions to back pain in old age: a study of 2,108 danish twins aged 70 and older. Spine 2004;29:897-901

14. Hakim AJ, Cherkas L, EL Zayet S, MacGregor AJ, spector TD. The genetic contribution to carpel tunnel syndrome in women: a twin study. Arthritis Rheum 2002;47:275-79

15. Zubieta JK,Heitzeg MM, Smith YR, et al COMT val158met genotype affects mu-opioid neurotransmitter responses to a pain stressor.Science 2003;299:1240-43

16. Diatchenko L, Slade GD, Nackley AG, et al. Genetic basis for individual variations in pain perception and the development of a chronic pain condition. Hum Mol Genet 2005;14:13543

17. Mogil JS, Wilson SG, Chesler EJ, et al. The melanocortin-1receptor gene medistes female -specific mechanisms of analgesia in mice and humans. Proc Natl Acad Sci USA 2003; 100:4867-72

18. Devor M, Raber P, Heritability of symptoms in an experimental model of neuropathic pain. Pain 1990; 42:51-67

19. Mogil JS, Wilson SG, Bon $\mathrm{K}$, et al . Heritability of nociception I: responses of 11 inbred mouse strains on 12 measures of nociception. Pain 1999;80;67-82 
20. Mogil JS, Yu L, Basbaum AI, Pain genes?: natural variation and transgenic mutants. Annu Rev Neurosci 2000; 23:777-811

21. Kalkman CJ, Visser K, Moen J, Bonsel GJ, Grobbee DE, Moons KG. Preoperative prediction of severe postoperative pain. Pain 2003;105:415-23

22. Werner MU, Dunn P, Kehlet H, prediction of postoperative pain by preoperative nociceptive responses to heat stimulation. Anaesthesiology 2004;100:115-19

23. Bisgaard T, Klarskov B, Rosenberg J, Kehlet H. Characteristics and prediction of early pain after laparoscopic cholecystectomy.Pain 2001;90:261-69

24. Bisgaard T, Rosenberg J, Kehlet H. from acute to chronic pain after laparoscopic cholecystectomy: a prospective follow-up analysis. Scand $J$ Gastroenterol 2005;40:1358-64

25. Grant AM, Scott NW, O’Dwyer PJ, MRC Laparoscopic Groin Hernia Trial Group. Five year follow-up of a randomized trial to assess pain and numbness after laparoscopic or open repair of groin hernia. $\mathrm{Br} J$ Surg 2004;91:1570-74

26. O’Dwyer PJ, Kingsnorth AN, Molloy RG, Small PK, Lammers B, Horeyseck G. Randomised clinical trial assessing impact of a lightweight or heavyweight mesh on chronic pain after inguinal hernia repair. $\mathrm{Br} J$ Surg;2005:92:166-70
27. Rogers ML, Henderson L, Mahajan RP, Duffy JP, Preliminary findings in the neurophysiological assessment of intercostal nerve injury during thoracotomy.Eur $J$ Cardiovasc Surg 1998; 115:841-47

28. Postoperative pain experience: results from a national survey suggest pain continues to be undermanaged.Anaesth Anal 2003;97:534-540

29. Brennan TJ, Kehlet H. Preventive analgesia to reduce wound hyperalgesia and persistent post surgical pain. Anaesthesiology 2005; 103:68183

30. Gottschalk A, Raja SN, Severing the link between acute and chronic pain: the anaesthesiologists role in preventive medicine.Anaesthesiology 2004;101:1063-65

31. Subramaniam K, Subramaniam B, Steinbrook RA. Ketamine as adjuvant analgesic to opioids: a quantitative and qualitative systematic review.Anesth Analg 2004;99:482-95

32. Dahl JB, Mathiesen O, Moiniche S. 'Protective premedication': an option with gabapentin and related drugs? A review of gabapentin and pregabalin in the treatment of postoperative pain. Acta Anaesthesiol Scand 2004;48:1130-36 